\title{
Prognostic Significance of Conversion Surgery Following First- or Second-line Chemotherapy for Unresectable Gastric Cancer
}

\author{
MINORU FUKUCHI, ERITO MOCHIKI, TORU ISHIGURO, YOUICHI KUMAGAI, \\ KEIICHIRO ISHIBASHI and HIDEYUKI ISHIDA \\ Department of Digestive Tract and General Surgery, \\ Saitama Medical Center, Saitama Medical University, Kawagoe, Japan
}

\begin{abstract}
Background/Aim: Advances in chemotherapy for gastric cancer have encouraged surgeons to perform conversion surgery following a response to first-line chemotherapy in patients with initially unresectable gastric cancer. In this study we evaluated the efficacy of conversion surgery following first- or second-line chemotherapy for unresectable gastric cancer. Patients and Methods: We retrospectively analyzed clinicopathological and survival data of 94 patients with unresectable gastric cancer treated with first- $(n=94)$ or second-line $(n=43)$ chemotherapy. Results: Patients who converted to surgery following first$(n=26)$ or second-line $(n=5)$ chemotherapy had significantly longer survival times than those treated with chemotherapy alone $(n=63)(p<0.01)$. Survival length did not differ significantly between patients converted to surgery following first-and second-line chemotherapy. Among 31 patients who underwent conversion surgery, one initial non-curative factor (odds $\operatorname{ratio}(O R)=0.49 ; \quad 95 \%$ confidence interval $(95 \% C I)=0.22-0.95 ; \quad p=0.03)$ was the only significant independent predictor of longer survival in multivariate Cox regression analysis. Conclusion: Patients with unresectable gastric cancer initially exhibiting one noncurative factor may obtain survival benefit from conversion surgery after a response to both first- and second-line chemotherapy.
\end{abstract}

Gastric cancer is the third most common cancer worldwide and the second leading cause of cancer death in Japan (1). Although early gastric cancer is largely a curable disease, advanced gastric cancer is still associated with poor survival.

Correspondence to: Minoru Fukuchi, MD, Department of Digestive Tract and General Surgery, Saitama Medical Center, Saitama Medical University, 1981 Kamoda, Kawagoe, Saitama 350-8550, Japan. Tel: +81 492283619, Fax: +81 492228865, e-mail: mfukuchi@saitama-med.ac.jp

Key Words: Unresectable gastric cancer, conversion surgery, firstor second-line chemotherapy.
The REGATTA trial, a phase III study, previously indicated the superiority of palliative gastrectomy following chemotherapy over chemotherapy alone for unresectable gastric cancer with one initial noncurative factor (2). For such patients, chemotherapy is thus the only possible treatment that is administered to provide palliative care and prolong survival. However, several novel chemotherapy regimens occasionally allow conversion of unresectable gastric cancer with one or more initial noncurative factors to resectable cancer. Recently, conversion surgery following first-line chemotherapy resulted in long-term survival in selected patients (3-11). Moreover, we previously showed that patients with unresectable gastric cancer obtained survival benefit from first-line chemotherapy and subsequent conversion surgery $(12,13)$.

In Japan, the SPIRITS trial established S-1 plus cisplatin (SP) as a standard first-line treatment for unresectable gastric cancer (14). Our previous phase II trial noted that S-1 plus paclitaxel (PTX), an alternative drug combination, has a similar efficacy to SP (15). Moreover, following the results of the G-SOX trial and REAL-2 trial, S-1 plus oxaliplatin (SOX) or capecitabine plus oxaliplatin (CapeOX) became options for first-line chemotherapy $(16,17)$. In human epidermal growth factor receptor-2-positive gastric cancer, cisplatin and capecitabine (XP) plus trastuzumab (T-mab) is the standard-of-care based on the ToGA trial (18). Following the results of the RAINBOW trial, PTX plus ramucirumab (Ram) emerged as a new standard-of-care for second-line chemotherapy (19), while (nab-)PTX, docetaxel (DTX), and irinotecan (IRI) were rated as options based on several trials.

Recent advances in chemotherapy for gastric cancer encouraged us to perform conversion surgery following a response to first-line chemotherapy in patients with initially unresectable gastric cancer. However, candidacy for conversion surgery following second-plus first-line chemotherapy has not yet been well evaluated. We instead retrospectively investigated the prognostic significance of conversion surgery following first- or second-line chemotherapy for patients with initially unresectable gastric cancer. 


\section{Patients and Methods}

Patients. We retrospectively reviewed a database of 94 patients with unresectable gastric cancer who underwent first-line chemotherapy at Saitama Medical Center of Saitama Medical University from May 2005 to August 2017. The study was approved by the Local Ethics Committee of Saitama Medical Center of Saitama Medical University (No. 613- II).

Tumor staging was performed according to Union for International Cancer Control pTNM staging guidelines, 7th edition (20). Terminology defined by the Japanese Gastric Cancer Association was used to avoid unnecessary confusion (21). Patients with unresectable gastric cancer were considered if they had at least one initially proven lesion with any noncurative factor, such as tumor invasion of adjacent structures (T4b); peritoneal (P1), hepatic (H1), and distant (M1) metastasis; or positive peritoneal cytology (CY1). The indication for conversion surgery was anticipation of curative resection after a response to chemotherapy (12).

Chemotherapy schedule. First- or second-line chemotherapy such as SP, SOX, CapeOX, S-1+PTX, XP+T-mab, PTX+Ram, (nab-)PTX, DTX, and IRI was used as the standard regimen according to established clinical trials (14-19). Tumor response was objectively assessed after each treatment course according to the Response Evaluation Criteria in Solid Tumors. Adverse events were evaluated by the Common Terminology Criteria for Adverse Events, version 4.0.

Statistical analysis. Continuous variables are expressed as medians and ranges. Patients' characteristics were compared using the $\chi^{2}$ test, Fisher's exact probability test, and the Mann-Whitney $U$-test. We calculated cumulative overall survival (OS) rates by the KaplanMeier method and compared survival curves with the log-rank test. OS was estimated from initial chemotherapy to the date of death or the last follow-up visit. Cox proportional hazard regression analysis was used to identify statistically significant independent factors for OS. Factors with a $p$-value $<0.05$ according to univariate analysis were assessed by multivariate analysis. In the univariate and multivariate analyses, odds ratios (ORs) with 95\% confidence intervals (CIs) were calculated. All statistical analyses were performed with JMP 5.0 software (SAS Institute Inc., Cary, NC, USA), and $p$-values $<0.05$ were considered statistically significant.

\section{Results}

Patients' characteristics. The characteristics of the 94 patients who underwent first-line chemotherapy are presented in Table I. There were 76 male and 18 female patients with a median age of 69 years (range $=31-82$ years). Of these, patients with one or more non-curative factors, $15(16 \%), 30(32 \%), 33(35 \%), 51$ (54\%), and 14 (15\%) had T4b, P1, H1, M1, and CY1 disease, respectively. Among 94 patients receiving first-line chemotherapy, 58 (62\%), seven (7\%), 24 (26\%), two (2\%), and three $(3 \%)$ patients received SP, S-1+PTX, SOX, CapeOX, and $\mathrm{XP}+\mathrm{T}-\mathrm{mab}$, respectively. Among 43 patients receiving secondline chemotherapy, three (7\%), four $(9 \%), 15(35 \%)$, four $(9 \%)$, $11(26 \%)$, and six (14\%) patients received PTX, DTX, nabPTX, IRI, PTX+Ram, and other treatments, respectively. Thirtyone patients $(33 \%)$ were converted to surgery.
The characteristics of these 31 patients are presented in Table II. There was a total of 27 male and four female patients with a median age of 68 years (range $=42-82$ years). Of these patients with one more noncurative factors, eight (26\%), $10(32 \%)$, six (19\%), $11(35 \%)$, and seven (23\%) had T4b, P1, H1, M1, and CY1 disease, respectively. Twenty-six patients $(84 \%)$ were treated with surgery following first-line chemotherapy and five (16\%) were treated following secondline chemotherapy. In first-line chemotherapy, 15 (58\%), four $(15 \%)$, and seven $(27 \%)$ patients received SP, S-1+PTX, and SOX, respectively. In second-line chemotherapy, two $(40 \%)$, one $(20 \%)$, and two $(40 \%)$ patients received PTX, nab-PTX, and PTX+Ram, respectively. After first- or second-line chemotherapy, two patients $(6 \%)$ had a complete response (CR), $22(71 \%)$ had a partial response (PR), and seven $(23 \%)$ had stable disease (SD). R0, R1, and R2 disease were found in $21(68 \%)$, eight (26\%), and two $(6 \%)$ patients, respectively.

Survival. The median OS of all 94 patients was 12 months, with a median follow-up time of 11 months (range=1-93 months). Among the 31 patients treated with surgery following first- and second-line chemotherapy (median time, 37 months), the 3-year OS rate was $42 \%$ and $50 \%$, respectively (Figure 1). Among the 63 patients treated with chemotherapy alone (median time, 9.4 months), the 3-year OS rate was $0 \%$ (Figure 1). Those patients who converted to surgery following first- or second-line chemotherapy had significantly longer OS times than those treated with chemotherapy alone $(p<0.01)$. The OS times did not differ significantly between patients converted to surgery following first- and second-line chemotherapy.

We selected the following 21 variables for univariate analysis with regard to OS among the 31 patients treated with conversion surgery: age ( $<68 v s . \geq 68$ years), gender (male vs. female), performance status (0vs. 1), location (upper $v s$. middle or lower), macroscopic type $(1,2$, or 3 vs. 4), histological type (G1 or 2 vs. G3), clinical tumor depth (T2-4a vs. T4b), clinical nodal stage (N0-2 vs. N3), P1 (yes vs. no), H1 (yes vs. no), M1 (yes vs. no), CY1 (positive $v s$. negative), number of noncurative factors (1 vs. 2 or 3), response (CR or PR vs. SD), toxicity grade (grade 1 or $2 v s$. grade 3 or 4), type of gastrectomy (distal vs. total), residual tumor ( $\mathrm{R} 0 v s . \mathrm{R} 1,2)$, pathological grade (grade 0 or $1 v s$. grade 2 or3), pathological tumor depth (T0-3 or $4 \mathrm{a} v s$. T4a or 4b), pathological nodal stage (N0 or 1 vs. N2 or 3), and pathological stage (I-III vs. IV). In univariate analysis, histological type $(p=0.05)$ and the number of non-curative factors $(p=0.02)$ were significantly associated with longer OS. In multivariate Cox regression analysis, one noncurative factor $(\mathrm{OR}=0.49$; 95\% $\mathrm{CI}=0.22$ $0.95 ; p=0.03)$ was an independent predictor of longer OS (Table III). 
Table I. Demographics of 94 patients with unresectable gastric cancer who underwent first- or second-line chemotherapy.

\begin{tabular}{|c|c|}
\hline \multicolumn{2}{|l|}{ Characteristics } \\
\hline Median age (range), years & $69(31-82)$ \\
\hline \multicolumn{2}{|l|}{ Gender, $\mathrm{n}$} \\
\hline Male/female & $76 / 18$ \\
\hline \multicolumn{2}{|l|}{ Performance status, $\mathrm{n}$} \\
\hline $0 / 1 / 2$ & $61 / 24 / 9$ \\
\hline \multicolumn{2}{|l|}{ Location, $\mathrm{n}$} \\
\hline Upper/middle/lower & $39 / 36 / 19$ \\
\hline \multicolumn{2}{|l|}{ Macroscopic type, $\mathrm{n}$} \\
\hline $0 / 1 / 2 / 3 / 4 / 5$ & $3 / 2 / 18 / 38 / 29 / 4$ \\
\hline \multicolumn{2}{|l|}{ Histological type, $\mathrm{n}$} \\
\hline $\mathrm{G} 1 / 2 / 3$ & $14 / 22 / 58$ \\
\hline \multicolumn{2}{|l|}{ Tumor depth, $\mathrm{n}$} \\
\hline $\mathrm{T} 1 \mathrm{~b} / 2 / 3 / 4 \mathrm{a} / 4 \mathrm{~b}$ & $3 / 3 / 19 / 54 / 15$ \\
\hline \multicolumn{2}{|l|}{ Nodal stage, $\mathrm{n}$} \\
\hline $\mathrm{N} 0 / 1 / 2 / 3$ & $16 / 13 / 25 / 40$ \\
\hline \multicolumn{2}{|l|}{ Peritoneal metastasis, $\mathrm{n}$} \\
\hline $\mathrm{P} 0 / 1$ & $64 / 30$ \\
\hline \multicolumn{2}{|l|}{ Hepatic metastasis, $n$} \\
\hline $\mathrm{H} 0 / 1$ & $61 / 33$ \\
\hline \multicolumn{2}{|l|}{ Distant metastasis, $\mathrm{n}$} \\
\hline $\mathrm{M} 0 / 1$ & $43 / 51$ \\
\hline \multicolumn{2}{|l|}{ Peritoneal cytology, n } \\
\hline Negative/positive & $80 / 14$ \\
\hline \multicolumn{2}{|l|}{ Number of noncurative factors, $n$} \\
\hline $1 / 2 / 3 / 4$ & $52 / 32 / 9 / 1$ \\
\hline \multicolumn{2}{|l|}{ First-line chemotherapy, $n$} \\
\hline S-1+cisplatin & 58 \\
\hline S-1+paclitaxel & 7 \\
\hline S-1+oxaliplatin & 24 \\
\hline Capecitabine+oxaliplatin & 2 \\
\hline Capecitabine+cisplatin+trastuzumab & 3 \\
\hline \multicolumn{2}{|l|}{ Response after first-line chemotherapy, $\mathrm{n}$} \\
\hline $\mathrm{CR} / \mathrm{PR} / \mathrm{SD} / \mathrm{PD}$ & $2 / 28 / 27 / 37$ \\
\hline \multicolumn{2}{|l|}{ Toxicity after first-line chemotherapy, $\mathrm{n}$} \\
\hline Grade $1 / 2 / 3 / 4$ & $10 / 16 / 26 / 10$ \\
\hline \multicolumn{2}{|l|}{ Second-line chemotherapy, $\mathrm{n}$} \\
\hline Paclitaxel & 3 \\
\hline Docetaxel & 4 \\
\hline Nab-paclitaxel & 15 \\
\hline Irinotecan & 4 \\
\hline Ramucirumab+paclitaxel & 11 \\
\hline Others & 6 \\
\hline \multicolumn{2}{|c|}{ Response after second-line chemotherapy, $\mathrm{n}$} \\
\hline $\mathrm{CR} / \mathrm{PR} / \mathrm{SD} / \mathrm{PD}$ & $1 / 4 / 9 / 29$ \\
\hline \multicolumn{2}{|c|}{ Toxicity after second-line chemotherapy, $\mathrm{n}$} \\
\hline Grade $1 / 2 / 3 / 4$ & $5 / 13 / 18 / 6$ \\
\hline \multicolumn{2}{|l|}{ Surgery, $\mathrm{n}$} \\
\hline No/yes & $63 / 31$ \\
\hline
\end{tabular}

CR: Complete response; PR: partial response; SD: stable disease; PD: progressive disease.

\section{Discussion}

According to recent advances in chemotherapy, conversion surgery following a response to chemotherapy is occasionally
Table II. Characteristics of 31 patients who underwent conversion surgery following first- or second-line chemotherapy.

\section{Characteristics}

Median age (range), years

Gender, $\mathrm{n}$

Male/female

$68(42-82)$

Performance status, $\mathrm{n}$

$0 / 1$

Location, $\mathrm{n}$

Upper/middle/lower

Macroscopic type, $\mathrm{n}$

$$
1 / 2 / 3 / 4
$$

Histological type, $\mathrm{n}$

G1/2/3

$4 / 6 / 21$

Clinical tumor depth, $\mathrm{n}$

$\mathrm{T} 2 / 3 / 4 \mathrm{a} / 4 \mathrm{~b}$

$1 / 4 / 18 / 8$

Clinical nodal stage, $\mathrm{n}$

N0/1/2/3

$6 / 5 / 7 / 13$

Peritoneal metastasis, $\mathrm{n}$

$\mathrm{P} 0 / 1$

$21 / 10$

Hepatic metastasis, $\mathrm{n}$

$\mathrm{H} 0 / 1$

Distant metastasis, $\mathrm{n}$

$\mathrm{M} 0 / 1$

$20 / 11$

Peritoneal cytology, $\mathrm{n}$

Negative/positive

$20 / 9 / 2$

First-line chemotherapy, $\mathrm{n}$

S-1+cisplatin

S-1+paclitaxel

S-1+oxaliplatin

15

4

Second-line chemotherapy, $\mathrm{n}$

Paclitaxel

Nab-paclitaxel

Ramucirumab+paclitaxel

Response after first or second-line chemotherapy, $\mathrm{n}$

$\mathrm{CR} / \mathrm{PR} / \mathrm{SD}$

7

2

1

2

Grade 1/2/3/4

$3 / 5 / 7 / 4$

Type of gastrectomy, $\mathrm{n}$

Distal/total

Residual tumor classification, $\mathrm{n}$

$\mathrm{R} 0 / 1 / 2$

Pathological response, $\mathrm{n}$

Grade $0 / 1 \mathrm{a} / 1 \mathrm{~b} / 2 / 3$

$4 / 9 / 5 / 11 / 2$

Pathological tumor depth, $\mathrm{n}$ ypT0/1/2/3/4a/4b

Pathological nodal stage, $\mathrm{n}$ yp $0 / 1 / 2 / 3$

Pathological stage, $\mathrm{n}$ ypStage0/I/II/III/IV

CR: Complete response; PR: partial response; SD: stable disease; PD: progressive disease.

associated with prolonged survival in patients with initially unresectable gastric cancer. To date, several studies have reported that conversion surgery following first-line chemotherapy results in long-term survival in selected 
Table III. Univariate and multivariate predictors of overall survival in 31 patients who underwent conversion surgery.

\begin{tabular}{|c|c|c|c|c|c|}
\hline \multirow[t]{2}{*}{ Variables } & \multirow[b]{2}{*}{$\mathrm{n}$} & \multicolumn{2}{|c|}{ Univariate } & \multicolumn{2}{|c|}{ Multivariate } \\
\hline & & Odds ratio $(95 \% \mathrm{CI})$ & $p$-Value & Odds ratio $(95 \% \mathrm{CI})$ & $p$-Value \\
\hline \multicolumn{6}{|c|}{ Histological type } \\
\hline $\mathrm{G} 1,2$ & 10 & $0.44(0.10-1.00)$ & 0.05 & $0.48(0.11-1.10)$ & 0.07 \\
\hline G3 & 21 & 1 & & 1 & \\
\hline \multicolumn{6}{|c|}{ Noncurative factors } \\
\hline 1 & 20 & $0.46(0.21-0.88)$ & 0.02 & $0.49(0.22-0.95)$ & 0.03 \\
\hline 2,3 & 11 & 1 & & 1 & \\
\hline
\end{tabular}

CI: Confidence interval.

patients (3-13). However, candidacy for conversion surgery following not only first-line but also second-line chemotherapy has been thoroughly evaluated. Our data showed that conversion surgery following second-line as well as first-line chemotherapy is associated with longer OS time among unresectable gastric cancer patients treated with chemotherapy. However, we propose that conversion surgery should be carefully performed in patients other than those with one initial noncurative factor.

Conversion surgery requires that patients have had a response to chemotherapy. Japanese guidelines indicate that chemotherapy regimens with an effective response are recommended for first-line to third-line treatments in patients with unresectable gastric cancer (22). As a first-line treatment, fluoropyrimidines plus platinum such as SP, XP (+T-mab), SOX, or CapeOX are generally used in Japan (22). Moreover, some studies have reported that docetaxel, cisplatin, and S-1 (DCS) therapy show a high response for this type of cancer, although grade 3 or 4 toxicity is more common in DCS than other therapies $(8,9)$. When conversion surgery was previously performed following a response to such an effective first-line chemotherapy, the rates of conversion surgery were $20-66 \%$ and median survival times were 26-56 months (3-13). In the present study, the rate of conversion surgery was $33 \%$ and the median survival time was 37 months, which is comparable to previous studies.

As second-line treatment, taxanes such as PTX (+Ram), DTX or nab-PTX, and IRI are generally used for patients with unresectable gastric cancer refractory to first-line treatment in Japan (22). These patients unusually have an effective response, so we believe that conversion surgery following second-line chemotherapy may be an option for unresectable gastric cancer under certain conditions. Although one study reported five cases who underwent conversion surgery following IRI after DCS therapy, they were inclusively handled as a DCS therapy group (9). In this study, when five patients with unresectable gastric cancer refractory to first-line chemotherapy were treated with second-line

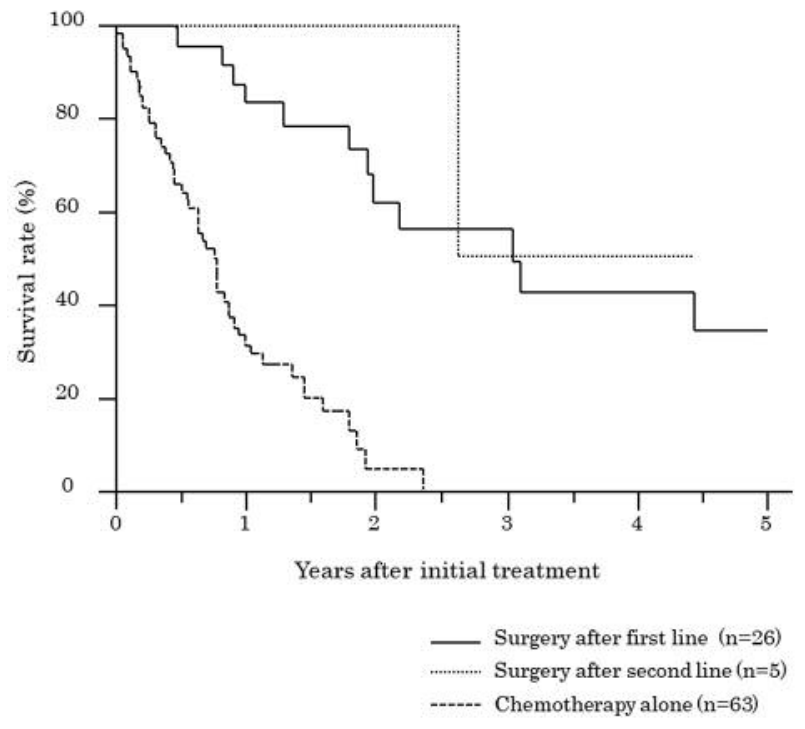

Figure 1. Cumulative overall survival (OS) of 94 patients treated with surgery after first- or second-line chemotherapy and chemotherapy alone. The cumulative OS of 26 and five patients treated with surgery following first- and second-line chemotherapy, respectively, was significantly better than that of 63 patients treated with chemotherapy alone $(p<0.01)$.

chemotherapy, they underwent conversion surgery after a response to second-line chemotherapy. These results showed the candidacy for conversion surgery following not only firstline but also second-line chemotherapy.

The REGATTA trial indicated the superiority of palliative gastrectomy following chemotherapy over chemotherapy alone for patients with unresectable gastric cancer with one initial noncurative factor (2). These patients are not considered candidates for surgery and so are usually offered chemotherapy. This contrasts with current findings and those of several previous studies reporting that conversion surgery after a response to chemotherapy results in longer survival than chemotherapy alone, even if patients have more than 
one initial noncurative factors (3-13). Additionally, the present study showed that one initial noncurative factor was an independent predictor of longer OS among patients treated with conversion surgery. This indicates that these patients may obtain a survival benefit from conversion surgery following first- or second-line chemotherapy (12).

In conclusion, conversion surgery after a response to chemotherapy may yield a survival benefit in unresectable gastric cancer patients, especially those with one initial noncurative factor. Recent advances in chemotherapy for gastric cancer enable us to perform conversion surgery following a response to first- or second-line chemotherapy in these patients. However, numerous obstacles remain to be overcome regarding the selection of first- or second-line chemotherapy and the indication or timing of conversion surgery. Although the current retrospective study was performed at a single center on a small patient population, and was therefore subject to selection bias, our findings should stimulate further inquiry into the management of initially unresectable gastric cancer. A prospective study with a larger series of cases is needed to evaluate conversion surgery following elective chemotherapy for this type of cancer.

\section{References}

1 Ferlay J, Soerjomataram I, Dikshit R, Eser S, Mathers C, Rebelo M, Parkin DM, Forman D and Bray F: Cancer incidence and mortality worldwide: sources, methods and major patterns in GLOBOCAN 2012. Int J Cancer 136: E359-386, 2015.

2 Fujitani K, Yang HK, Mizusawa J, Kim YW, Terashima M, Han SU, Iwasaki Y, Hyung WJ, Takagane A, Park DJ, Yoshikawa T, Hahn S, Nakamura K, Park CH, Kurokawa Y, Bang YJ, Park BJ, Sasako $\mathrm{M}$ and Tsujinaka T: Gastrectomy plus chemotherapy versus chemotherapy alone for advanced gastric cancer with a single non-curable factor (REGATTA): a phase 3, randomised controlled trial. Lancet Oncol 17: 309-318, 2016.

3 Nakajima T, Ota K, Ishihara S, Oyama S, Nishi M, Ohashi Y and Yanagisawa A: Combined intensive chemotherapy and radical surgery for incurable gastric cancer. Ann Surg Oncol 4: 203-208, 1997.

4 Suzuki T, Tanabe K, Taomoto J, Yamamoto H, Tokumoto N, Yoshida $\mathrm{K}$ and Ohdan $\mathrm{H}$ : Preliminary trial of adjuvant surgery for advanced gastric cancer. Oncol Lett 1: 743-747, 2010.

5 Kanda T, Yajima K, Kosugi S, Ishikawa T, Ajioka Y and Hatakeyama K: Gastrectomy as a secondary surgery for stage IV gastric cancer patients who underwent S-1-based chemotherapy: a multi-institute retrospective study. Gastric Cancer 15: 235-244, 2012.

6 Yabusaki H, Nashimoto A, Matsuki A and Aizawa M: Significance of surgical treatment in multimodal therapy for stage IV highly advanced gastric cancer. Hepatogastroenterology 60: 377-381, 2013.

7 Ito S, Oki E, Nakashima Y, Ando K, Hiyoshi Y, Ohgaki K, Saeki $\mathrm{H}$, Morita M, Sakaguchi Y and Maehara Y: Clinical significance of adjuvant surgery following chemotherapy for patients with initially unresectable stage IV gastric cancer. Anticancer Res 35: 401-406, 2015.
8 Kinoshita J, Fushida S, Tsukada T, Oyama K, Okamoto K, Makino I, Nakamura K, Miyashita T, Tajima H, Takamura H, Ninomiya I and Ohta T: Efficacy of conversion gastrectomy following docetaxel, cisplatin, and S-1 therapy in potentially resectable stage IV gastric cancer. Eur J Surg Oncol 41: 13541360, 2015.

9 Sato Y, Ohnuma H, Nobuoka T, Hirakawa M, Sagawa T, Fujikawa K, Takahashi Y, Shinya M, Katsuki S, Takahashi M, Maeda M, Okagawa Y, Naoki U, Kikuch S, Okamoto K, Miyamoto H, Shimada M, Ichiro T, Kato J and Takayama T: Conversion therapy for inoperable advanced gastric cancer patients by docetaxel, cisplatin, and S-1 (DCS) chemotherapy: a multi-institutional retrospective study. Gastric Cancer 20: 517-526, 2017.

10 Yamaguchi K, Yoshida K, Tanahashi T, Takahashi T, Matsuhashi $\mathrm{N}$, Tanaka Y, Tanabe $\mathrm{K}$ and Ohdan $\mathrm{H}$ : The long-term survival of stage IV gastric cancer patients with conversion therapy. Gastric Cancer 21: 315-323, 2018.

11 Morgagni P, Solaini L, Framarini M, Vittimberga G, Gardini A, Tringali D, Valgiusti M, Monti M and Ercolani G: Conversion surgery for gastric cancer: A cohort study from a western center. Int J Surg 53: 360-365, 2018.

12 Fukuchi M, Ishiguro T, Ogata K, Suzuki O, Kumagai Y, Ishibashi $\mathrm{K}$, Ishida $\mathrm{H}$, Kuwano $\mathrm{H}$ and Mochiki E: prognostic role of conversion surgery for unresectable gastric cancer. Ann Surg Oncol 22: 3618-3624, 2015.

13 Fukuchi M, Mochiki E, Ishiguro T, Ogura T, Sobajima J, Kumagai $\mathrm{Y}$, Ishibashi $\mathrm{K}$ and Ishida $\mathrm{H}$ : Efficacy of conversion surgery following S-1 plus cisplatin or oxaliplatin chemotherapy for unresectable gastric cancer. Anticancer Res 37: 1343-1347, 2017.

14 Koizumi W, Narahara H, Hara T, Takagane A, Akiya T, Takagi M, Miyashita K, Nishizaki T, Kobayashi O, Takiyama W, Toh Y, Nagaie T, Takagi S, Yamamura Y, Yanaoka K, Orita $H$ and Takeuchi M: S-1 plus cisplatin versus S-1 alone for first-line treatment of advanced gastric cancer (SPIRITS trial): a phase III trial. Lancet Oncol 9: 215-221, 2008.

15 Mochiki E, Ogata K, Ohno T, Toyomasu Y, Haga N, Fukai Y, Aihara R, Ando H, Uchida N, Asao T and Kuwano H; North Kanto Gastric Cancer Study Group: Phase II multi-institutional prospective randomised trial comparing $\mathrm{S}-1+$ paclitaxel with $\mathrm{S}$ $1+$ cisplatin in patients with unresectable and/or recurrent advanced gastric cancer. Br J Cancer 107: 31-36, 2012.

16 Yamada Y, Higuchi K, Nishikawa K, Gotoh M, Fuse N, Sugimoto N, Nishina T, Amagai K, Chin K, Niwa Y, Tsuji A, Imamura H, Tsuda M, Yasui H, Fujii H, Yamaguchi K, Yasui H, Hironaka S, Shimada K, Miwa H, Hamada $\mathrm{C}$ and Hyodo I: Phase III study comparing oxaliplatin plus S-1 with cisplatin plus S-1 in chemotherapy-naïve patients with advanced gastric cancer. Ann Oncol 26: 141-148, 2015.

17 Cunningham D, Starling N, Rao S, Iveson T, Nicolson M, Coxon F, Middleton G, Daniel F, Oates J and Norman AR: Capecitabine and oxaliplatin for advanced esophagogastric cancer. N Engl J Med 358: 36-46, 2008.

18 Bang YJ, Van Cutsem E, Feyereislova A, Chung HC, Shen L, Sawaki A, Lordick F, Ohtsu A, Omuro Y, Satoh T, Aprile G, Kulikov E, Hill J, Lehle M, Rüschoff $J$ and Kang YK: Trastuzumab in combination with chemotherapy versus chemotherapy alone for treatment of HER2-positive advanced gastric or gastro-oesophageal junction cancer (ToGA): a phase 3, open-label, randomised controlled trial. Lancet 376: 687-697, 2010. 
19 Wilke H, Muro K, Van Cutsem E, Oh SC, Bodoky G, Shimada Y, Hironaka S, Sugimoto N, Lipatov O, Kim TY, Cunningham D, Rougier P, Komatsu Y, Ajani J, Emig M, Carlesi R, Ferry D, Chandrawansa K, Schwartz JD and Ohtsu A: Ramucirumab plus paclitaxel versus placebo plus paclitaxel in patients with previously treated advanced gastric or gastro-oesophageal junction adenocarcinoma (RAINBOW): a double-blind, randomised phase 3 trial. Lancet Oncol 15: 1224-1235, 2014.

20 Sobin LH, Gospodarowicz MK and Wittekind CH: TNM Classification of Malignant Tumours. Seven Edition. Oxford: Wiley-Blackwell, 2009.
21 Japanese Gastric Cancer Association: Japanese classification of gastric carcinoma: Third English edition. Gastric Cancer 14: 101-112, 2011.

22 Japanese Gastric Cancer Association: Japanese gastric cancer treatment guidelines 2014 (ver. 4). Gastric Cancer 20: 1-19, 2016.

Received September 22, 2018

Revised October 2, 2018

Accepted October 3, 2018 